\title{
Comparative Three Dimensional CFD Study for Inline Cross Flow Plate Finned Tube Heat Exchanger
}

\author{
M. Shawky Ismail ${ }^{\mathbf{1}}$, M. Hassab ${ }^{\mathbf{1}}$, Wael M. El-Maghlany ${ }^{1}$ \\ ${ }^{1}$ Faculty of Engineering, Alexandria University \\ Egypt \\ eng_mh2005@yahoo.com; mohammedhassab46@gmail.com; elmaghlany@alexu.edu.eg
}

\begin{abstract}
In this paper, three dimensional study has been investigated on finned-tubes cross flow heat exchanger. The investigation takes into account the outer cold fluid flow (air). The inner hot fluid flow (water) and the conjugated solid domain. The hot water flowing inside the tube is considered laminar while the air flowing outside the tubes inside the fin passages is treated as turbulent. All heat transfer and fluid flow parameters have been studied at different velocities for air in the range between 1 -to- $6 \mathrm{~m} / \mathrm{s}$ with fixed Re $=1200$ for inner water flow. In this study, the heat transfer coefficients and pressure drops on both sides of fluids are calculated numerically for both the conventional size and the selected micro size heat exchangers with plain-tube and finned-tubes arrangements. The results declare that the micro tube has higher performance with controllable pressure drop as the heat flux ratio is increased by $20 \%$ whereas, the heat per unit volume ratio is increased by $800-1200 \%$ with the increase of air velocity from the given lower to the higher one. It is found that the effects of using fins are profitable only for the conventional exchanger but not for the micro size exchanger. The most interesting results obtained from this study is the superiority of the micro tube heat exchangers over the typically conventional one in regards of the heat transfer rate per unit volume.
\end{abstract}

Keywords: Finned tube heat exchanger, CFD simulation, turbulent flow, conjugate heat transfer, plain fin, micro channel heat exchanger.

\section{Nomenclature}

$\begin{array}{clcl}\mathrm{A} & \text { Base area, } \mathrm{m}^{2} & \mathrm{x}, \mathrm{y}, \mathrm{z} & \text { coordinate axes } \\ \mathrm{C}_{\mathrm{p}} & \text { specific heat, } \mathrm{J} / \mathrm{kg} . \mathrm{K} & \mathrm{S} & \text { center to center fin spacing } \\ \mathrm{d} & \text { diameter, } \mathrm{m} & \mathrm{W} & \text { width of domain( pass of the air) } \\ \mathrm{h} & \text { heat transfer coefficient, } \mathrm{W} / \mathrm{m}^{2} \mathrm{~K} & \Delta T_{l m} & \text { Logarithmic mean temperature difference } \\ \mathrm{k} & \text { thermal conductivity, W/m K } & \text { Greek symbols } & \\ \mathrm{L} & \text { length of tube, } \mathrm{m} & \mu & \text { viscosity } \\ \mathrm{N} & \text { no of tubes } & \eta & \text { efficiency } \\ \mathrm{NTU} & \text { number of transfer unit } & \rho & \text { density } \\ \mathrm{Nu} & \text { Nusselt number } & \text { Subscripts } & \\ \mathrm{P} & \text { pitch, } \mathrm{m} & \mathrm{i}, \mathrm{j} & \text { index notation for Cartesian coordinates } \\ \mathrm{Q} & \text { rate of heat transfer, W } & \text { in } & \text { inlet } \\ \mathrm{q} & \text { Heat flux, W/m }{ }^{2} & \text { out } & \text { outlet } \\ \text { Re } & \text { Reynolds number } & \mathrm{f} & \text { fin } \\ \mathrm{t} & \text { Fin thickness, mm } & \text { wf av } & \text { average of fin surface } \\ \mathrm{T} & \text { temperature, } \mathrm{K} & \mathrm{a} \mathrm{av} & \text { air passage average } \\ \mathrm{u} & \text { Velocity vector, } \mathrm{m} / \mathrm{s} & \text { bf av } & \text { base of fin on tube average } \\ \mathrm{U} & \text { Inlet velocity, } \mathrm{m} / \mathrm{s} & & \end{array}$




\section{Introduction}

Designing highly compact and micro heat exchanger is under focus research recent years. The configuration of one fluid flow inside regular circular cross section tube and the other fluid crossover the tubes is the most configuration used nowadays.

The previous studies show that the performance can be influenced by many factors like tube diameter size, pitch in transverse and longitudinal direction, thickness of fin, material of fin, fin geometry, etc. the tube bank with fins has been investigated by $[1,2]$. And this investigation carried out on the outer fluid only and different pitch sizes. Wang et al, [35] studied the finned tube experimentally and numerically for plan fin and wavy type for the conventional size. Pirompugd et al, [6] studied the effect of the wetting surface of the wavy fin. Rocha et al [7] have been developed a numerical simulation to make comparison between two tube geometry which is the circular and elliptic one at low Reynolds number. They show that the elliptic configuration performance is better than the circular performance. Despite that, the manufacturing and costing are favour of circular tube and against of the elliptic one. Chi-Wen Lu et al [8] have been conducted numerically the influence of the fin pitch, tube diameter, longitudinal and transverse pitch, fin thickness for two tube rows only. His study concluded that decreasing the diameter will increase the heat transfer per pressure drop. The study didn't take into account the inner fluid and go to mini channel scale or micro scale. And also the investigation didn't mention the bare tubes and the performance as NTU or overall heat transfer or fin efficiency.

Zukauskas [9] performed experimental work which is the major and the base pivot for all coming researches in all type geometrical flow across tube bank without fins. This study came out with powerful correlation with an error up to $15 \%$ for Nusselt number. The most researches prior to 2000 were experimentally and after that the numerical becomes dominant because of enormous growth in computing power. Buyruk [10] studied the inline and the staggered arrangement in low Reynolds number from 80-400 for fixed longitudinal and transverse pitch ratio of 2 and for two rows only.

From the above research studies, it is clear that the previous research works on micro heat exchangers had concentrated on the study of heat transfer only in the fluid flow on the outer-side of the tubes numerically and experimentally without considering the participation of the fluid flowing inside the tubes. There assumption was done by considering the outer tube surfaces subjected to isothermal boundary condition.

In the present work, the heat transfer analysis considered the variations of flow parameters in the entire regions of the micro and conventional cross flow heat exchangers, including the inner fluid region, the tube and fin passages, and the outer fluid region. Analysis for heat transfer and fluid flow in each passage of air and water flow inside tube are solved numerically using CFD software model.

\section{Problem statement and numerical methodology}

In this study, the simulations are investigated with commercial code fluent 6.3(ANSYS17) on finned-tube heat exchanger with plan fin configuration and without fin to make comparison between both cases. In the program it has been selected laminar flow for the inner water and turbulent flow with realizable $K-\varepsilon$ turbulent mode with enhanced wall treatment to have more accurate results at the wall [8]. The influence of velocity and tube diameter has been studied and summarized in Table 1. A schematic of the heat exchanger is shown in Fig 1 and the analysis of all cases is carried out with some of considered assumptions:

- Incompressible flow for both fluids and constant thermo-physical properties is to be considered.

- Laminar flow for inside tube as range of $R e$ is less than 2300.

- Turbulent flow for the outer fluid as the range of Re is in the turbulent mode as mentioned before.

- Steady state condition, Three-dimensional flow inside and outer the tube.

- The axial conduction is neglected across the thin tube wall thickness and thus the tube wall is handled as interface between the inner fluid and outer fluid. 

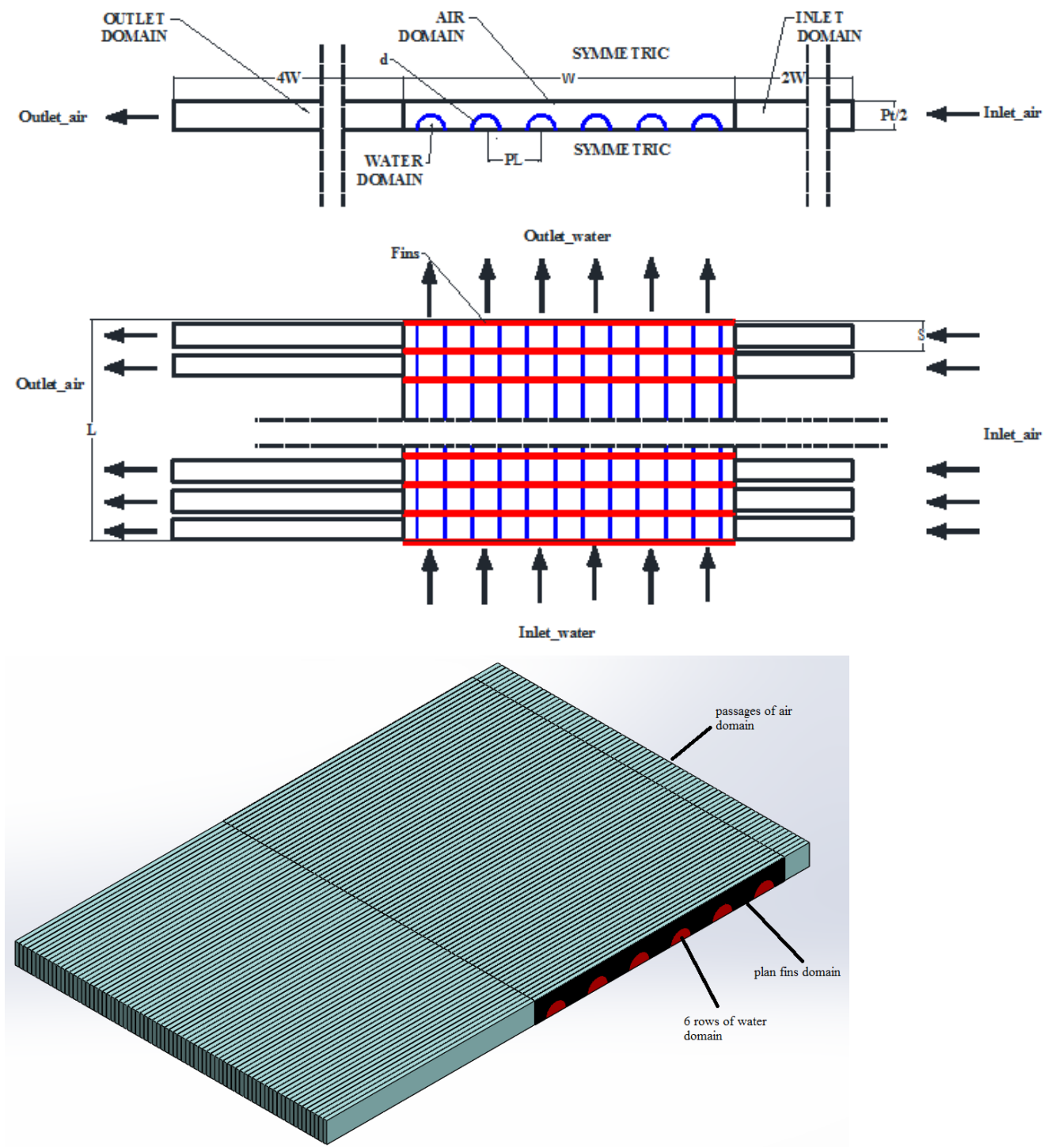

Fig. 1: Schematic of the computational domain with extended inlet and outlet domains.

Table 1: Studied parameters, all lengths in $m m$, temperature in $K$.

\begin{tabular}{|c|c|c|c|c|c|c|c|c|c|c|c|c|c|}
\hline Parameter & $d$ & $U(m / s)$ & $P_{t} / d$ & $P_{L} / d$ & $t$ & $W$ & $L$ & $S$ & $N_{f}$ & $N_{t}$ & $R e$ & $T_{a_{\_} \text {in }}$ & $T_{w_{\_} \text {in }}$ \\
\hline value & 1,10 & $1-6$ & 2 & 2 & 0.4 & $6 \times P_{L}$ & 0.15 & 2.0 & 75 & 6 & 1200 & 300 & 363 \\
\hline
\end{tabular}

The boundary conditions for air domain in velocity inlet at the beginning of the inlet domain and pressure outlet at the end of outlet domain as shown in Fig 1 in Z- direction. The above and bottom surfaces is symmetrical boundary condition in Y-direction. Each passage of air contained by wall fin surface from sides, this is interfacing boundary condition for conjugate solution. The boundary condition of water is mass flow inlet and pressure outlet in X-direction. The bottom surface is symmetrical the circumference of the tube is interface boundary condition with air in segments and fins in the other segments as illustrated in equations (6-12). 
Mesh independence was created carefully and make sub domains to insure good mesh at interfaces which the most variation of fluid flow and heat transfer rates. The modal assessed by residual 10-6 for all parameters except energy 10solving equation continuity, momentum equations in three direction and two turbulence equation and energy equation. equations is solved by applying SIMPLE algorithm which is performed with Least Squares Cell-Based discretization with second order upwind accuracy for all parameters (pressure, momentum, turbulent kinetic energy, turbulent rate and energy. And also checked the total summation of mass flow rate and energy balance for the all domain which is less than $0.1 \%$ from lowest value.

\section{Governing equations}

The governing equations of the water and air flow through the heat exchanger, Fig 1 define by the continuity and momentum equations in vector form, kinetic and turbulent dissipation equations [11] and energy equation are written as follows:

$$
\begin{gathered}
\frac{\partial u_{i}}{\partial x_{i}}=0.0 \\
\rho \frac{\partial}{\partial x_{j}}\left(u_{i} u_{j}\right)=-\frac{\partial P}{\partial x_{i}}+\frac{\partial}{\partial x_{j}}\left[\mu\left(\frac{\partial u_{i}}{\partial x_{j}}+\frac{\partial u_{j}}{\partial x_{i}}\right)\right]+\frac{\partial}{\partial x_{j}}\left(-\rho \overline{u_{\imath}^{\prime} u_{j}^{\prime}}\right) \\
\rho \frac{\partial}{\partial x_{j}}\left(u_{i} K\right)=\frac{\partial}{\partial x_{j}}\left[\left(\mu+\frac{\mu_{t}}{\sigma_{k}}\right) \frac{\partial K}{\partial x_{j}}\right]+G_{k}+G_{b}-\rho \varepsilon+Y_{m}+S_{k} \\
\rho \frac{\partial}{\partial x_{j}}\left(u_{i} \varepsilon\right)=\frac{\partial}{\partial x_{j}}\left[\left(\mu+\frac{\mu_{t}}{\sigma_{\varepsilon}}\right) \frac{\partial \varepsilon}{\partial x_{j}}\right]+C_{1 \varepsilon} \frac{\varepsilon}{K}\left(G_{k}+C_{3 \varepsilon} G_{b}\right)-C_{2 \varepsilon} \rho \frac{\varepsilon^{2}}{K}+S_{\varepsilon} \\
\rho c_{p} \frac{\partial T u_{i}}{\partial x_{i}}=\frac{\partial}{\partial x_{i}}\left(k+k_{t}\right) \frac{\partial T}{\partial x_{i}}
\end{gathered}
$$

Inlet boundary condition for air domain, mass flow inlet for water domain based on fixed $R e=1200$

$$
\begin{gathered}
u=U \quad v=w=0 \quad T=T a_{-} i n \\
w=\frac{R e * \mu}{\rho * d} \quad v=u=0 \quad T=T w_{-} i n
\end{gathered}
$$

Pressure outlet boundary condition for air and water domain

$$
\begin{aligned}
& \frac{\partial u}{\partial z}=\frac{\partial v}{\partial z}=\frac{\partial w}{\partial z}=\frac{\partial T}{\partial z}=0 \\
& \frac{\partial u}{\partial x}=\frac{\partial v}{\partial x}=\frac{\partial w}{\partial x}=\frac{\partial T}{\partial x}=0
\end{aligned}
$$


Symmetrical boundary condition at upper and lower surfaces in Y-Direction for air, water and fins.

$$
\begin{array}{ccc}
\frac{\partial u}{\partial y}=\frac{\partial w}{\partial y}=0 \quad v=0 & \frac{\partial T}{\partial y}=0 \\
u=v=w=0 & \frac{\partial T}{\partial y}=0
\end{array}
$$

Tube wall surface interface between water to fins base in some segments and air to water in the other segments. Fins interface to air at its outer surface

$$
u=v=w=0 \quad k_{f} \frac{\partial T}{\partial n}=k_{w} \frac{\partial T}{\partial n} \quad k_{a} \frac{\partial T}{\partial n}=k_{w} \frac{\partial T}{\partial n} \quad k_{f} \frac{\partial T}{\partial n}=k_{a} \frac{\partial T}{\partial n}
$$

The above governing equations (1-5) together with their boundary conditions equations (6-12) is solved numerically for obtaining velocity, pressure, temperature distribution for the inner and outer fluid using the above defend software. Taking into consideration that the properties of the fluid and solid is constant at the following Table2.

Table 2: the fluid and fins properties.

\begin{tabular}{|c|c|c|c|}
\hline property & air & water & fins \\
\hline$\rho$ & 1.164 & 965.3 & 2719 \\
\hline $\mathrm{C}_{\mathrm{p}}$ & 1007 & 4206 & 871 \\
\hline$\mu$ & $1.872 \times 10^{-5}$ & $0.315 \times 10^{-3}$ & ----- \\
\hline $\mathrm{k}$ & 0.02588 & 0.675 & 202.4 \\
\hline
\end{tabular}

Fig 2 shows the meshing and its adaption to have low skewness value less than 0.6 and orthogonal quality more than 0.4 . The approximate number of cells is $9.13 \times 10^{6}$ cells.

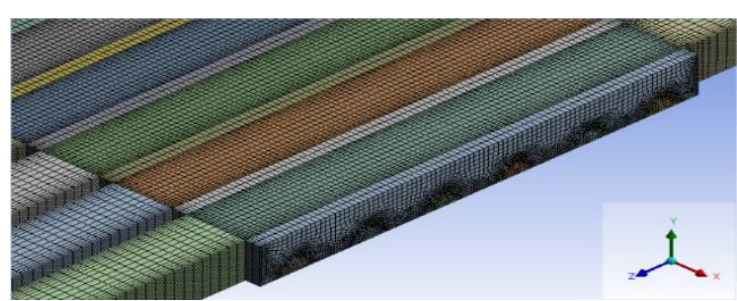

(A)

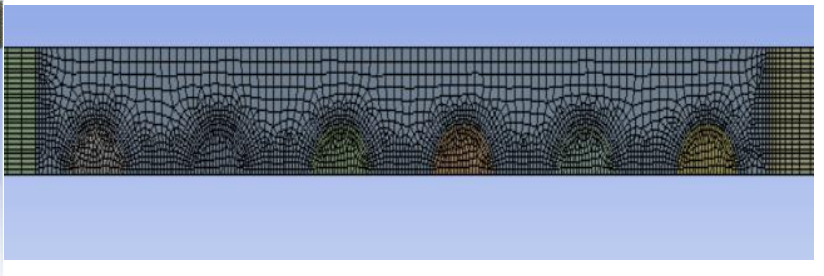

(B)

Fig. 2: Schematic of the mesh grid (A) part of the domain (B) the mesh in tubes and around it.

\section{Mesh independence and validation}

To be confident of grid, Fig 3 shows the rate of heat transfer for diameter $1 \mathrm{~mm}$ and $1 \mathrm{~cm}$. The satisfied number of grids is $4 \times 106$ for pipe diameter of $1 \mathrm{~mm}$ and $9 \times 106$ for pipe diameter of $1 \mathrm{~cm}$. In addition the present numerical solution is validated with experimental work [4] and also numerical work [13], Fig.4. The comparison shows good agreement between the present code and previous results with maximum deviation only up to $8 \%$. 


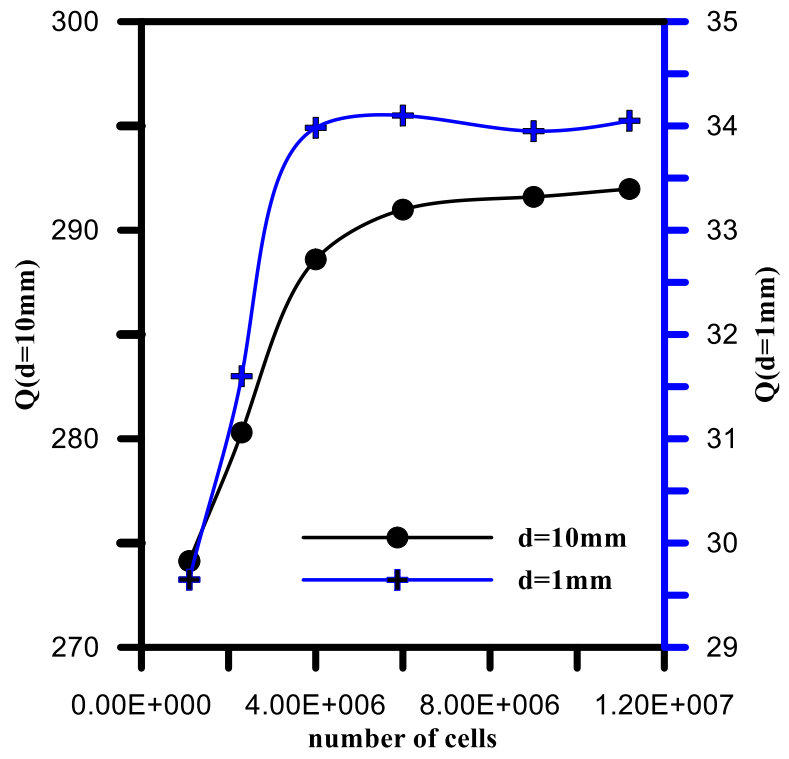

Fig. 3: Grid independence.

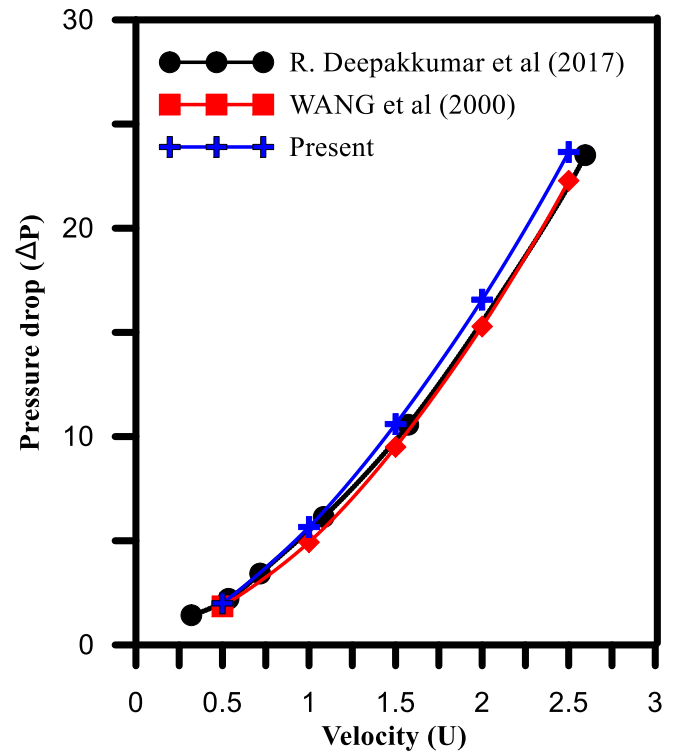

Fig. 4: Validation results.

Before presenting the results, the following definitions of the thermal analysis will be introduced representing system parameters such as Reynolds number, heat transfer coefficient, logarithmic mean temperature, Nusselt number, fin efficiency as follow:

$$
R e=\frac{\rho U_{\max } d}{\mu}, h=\frac{q}{\Delta T_{l m}}, \Delta T_{l m}=\frac{\left(T_{i}-T_{w a v}\right)-\left(T_{o u t}-T_{w a v}\right)}{\ln \frac{\left(T_{i}-T_{w a v}\right)}{\left(T_{o u t}-T_{w} a v\right)}}, N u=\frac{h d}{k}, \eta_{f}=\frac{T_{w f a v}-T_{a} a v}{T_{b f a v}-T_{a} a v}
$$

\section{Results and discussions}

With the aids of Eq. 6, comparison between conventional inline heat exchanger with mini channels including extended surface like straight fins with micro channels with the same conditions except the pipe diameter. The comparison includes the effect of surface temperature change in the tube surface against isothermal assumption in the most previous studies. Fig 5 represents the effect of the air velocity on the amount of heat transfer rate; it is found that the rate of heat transfer is proportionally with the surface area, in other words, mini channels with finned tube gave the largest heat transfer rate. This results do not mean the mini channels are favorable than the micro. The good comparison will be preferable if the heat rate is replaced by heat flux rate, Fig. 7. The results in Fig. 7 demonstrate that the micro channel with high air velocity (weak heat transfer coefficient side) gives high heat transfer rate in compared to the other configurations. The high heat transfer rate for finned tube micro channel could be explained via the air side heat transfer coefficient $(h=N u k / w)$, Fig. 6 and the water side heat transfer coefficient $((h=N u k / d)$, Fig. 9. The air side heat transfer coefficient is not affected with the tube diameter due to its dependence on the channel width while the heat transfer coefficient of approximately increases via 10 times for micro channel than the mini one. The results in Fig. 9 shows that for micro channels the heat transfer coefficient is more than the heat transfer coefficient for mini channels in the absence of the fins utilization. The problem in the utilization of micro channels is the pressure drop penalty in the water side which has been investigated in previous studies. the water pumping power is very small in compared to the air pumping power that is given in Fig. 8, the micro channels tubes gives responsible pressure drop penalty with high heat transfer flux.

Fig 10 gives the mean average temperature considering both heat transfer working medium (air and water). Bare tube in both micro and mini channels could be considered as isothermal wall conditions assumption while in the finned tube this assumption is not accurate enough. The fin efficiency varies from 0.97 to .91 for $\mathrm{d}=10 \mathrm{~mm}$ domain and from 0.9998 to 0.999 
for $\mathrm{d}=1 \mathrm{~mm}$ as the effective length of the fin is about $1 \mathrm{~mm}$ for a pitch as twice diameter. So the resistance of the fin is very low compared to the conventional one.

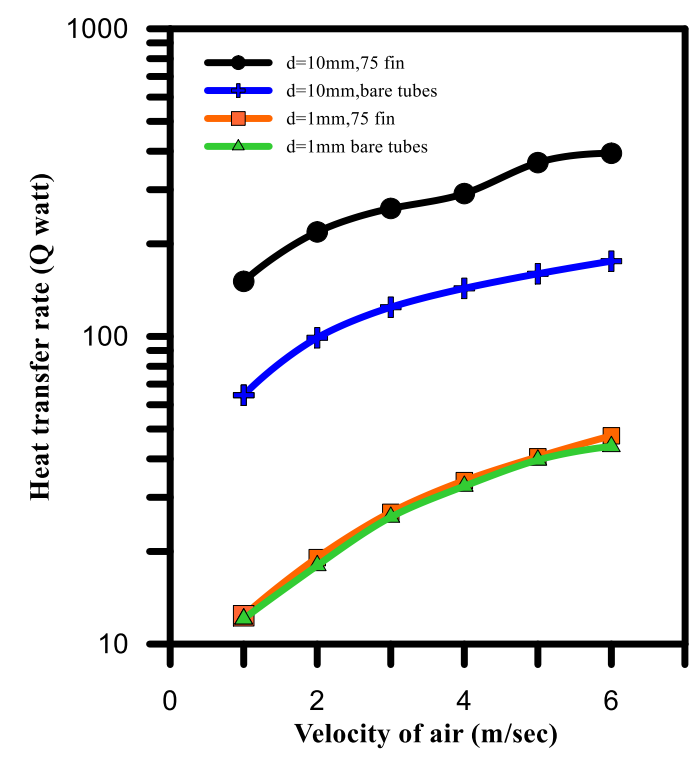

Fig. 5: The heat transfer rate in watt.

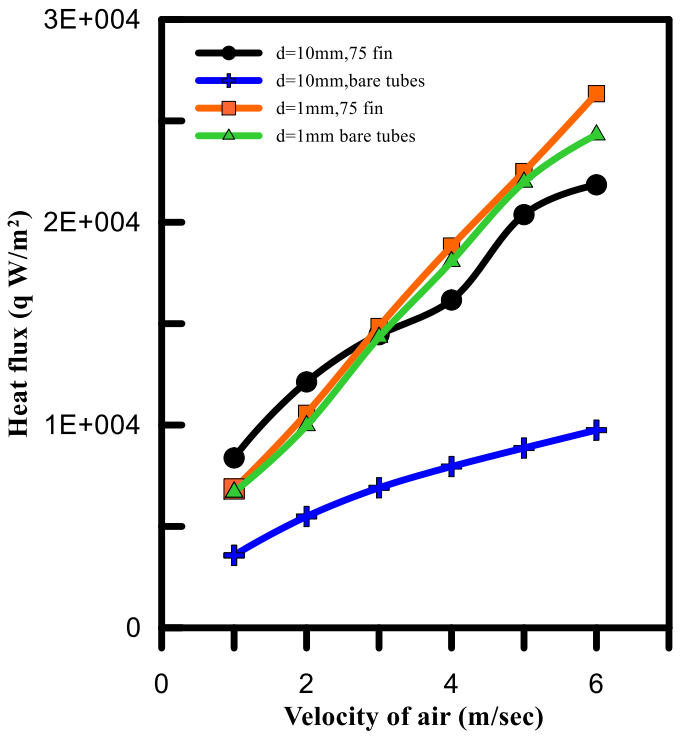

Fig. 7: Heat flux $\left(\mathrm{Q} / \mathrm{A}_{\text {base }}\right)$.

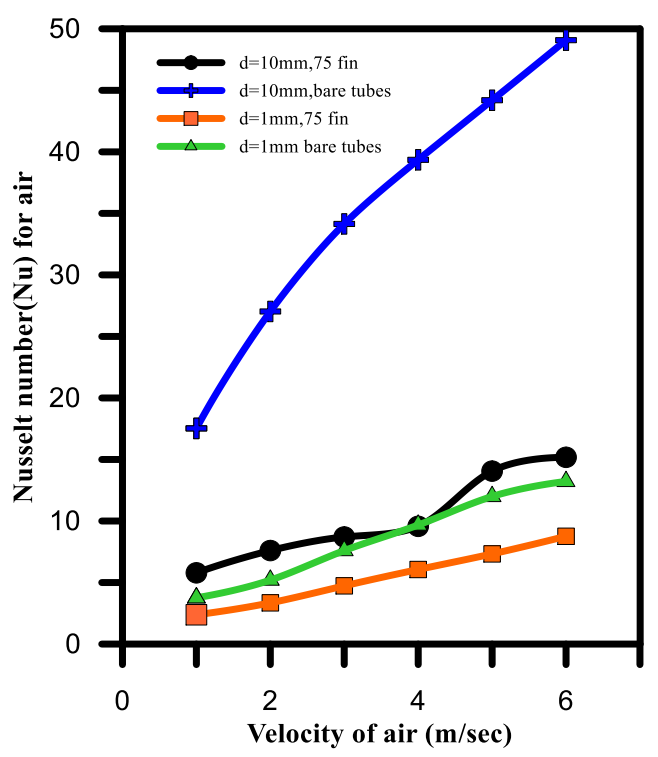

Fig. 6: Nusselt number of air $(\mathrm{Nu})$.

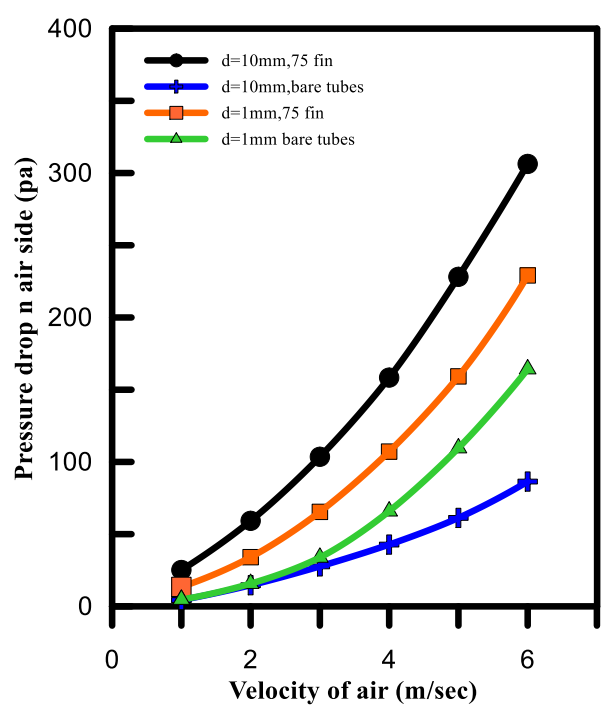

Fig. 8: Pressure drop(pa). 


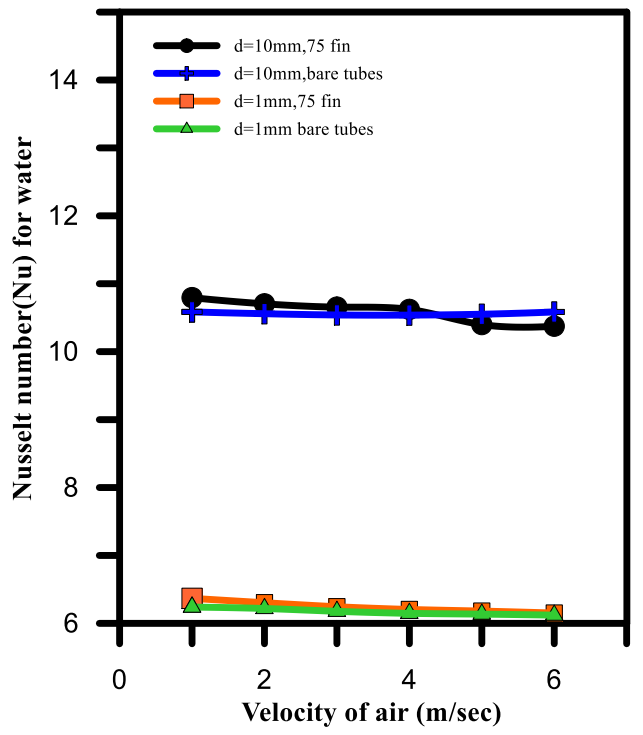

Fig. 9: Nusselt number of water.

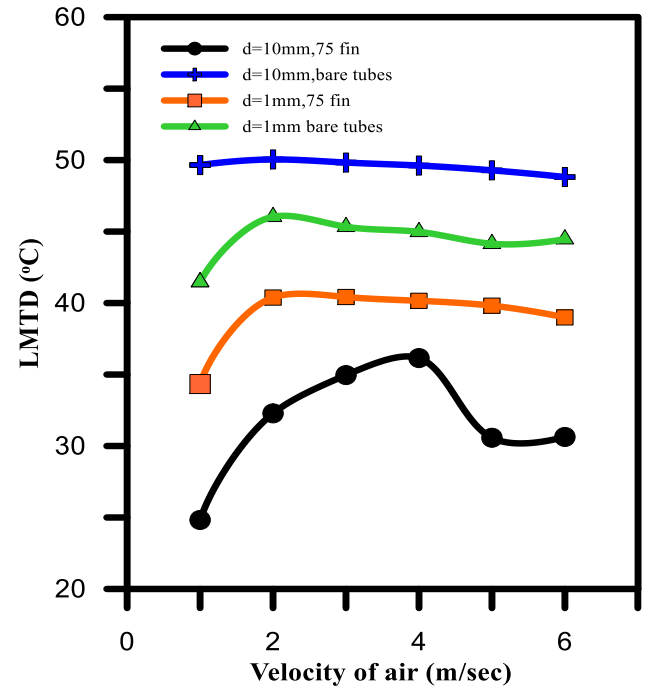

Fig. 10: LMTD for air side.

\section{Conclusion}

The following concluded results could be carried out from the present investigation.

- The micro tubes performance is much better than the conventional tubes with realizable pressure drop due to lower surface area of fins.

- Plan straight fins have a limited effect on the conventional cross flow heat exchanger due to the pulling down of heat transfer coefficient with respect to shear stress.

- Bare micro tubes have better performance than the finned one, so it is recommended over finned one.

- Isothermal wall boundary condition gives a higher value of heat transfer coefficient which could be established with phase change inside the tubes (boiling or condensation).

\section{References}

[1] S. Wongwises, Y. Chokeman, "Effect of fin pitch and number of tube rows on the air side performance of herringbone wavy fin and tube heat exchangers," Energy Convers. Manage, vol. 46, pp. 2216-2231, 2005.

[2] Y. B. Tao, Y. L. He, J. Huang, Z. G. Wu, W. Q. Tao, "Three-dimensional numerical study of wavy fin-and-tube heat exchangers and field synergy principle analysis," Int. J. Heat Mass Transfer, vol. 50, pp. 1163-1175, 2007.

[3] C. C. Wang, K. Y. Chi, C. J. Chang, "Heat transfer and friction characteristics of plain fin-and-tube heat exchangers, part II: correlation," Int. J. Heat Mass Transfer, vol. 43, pp.2693-2700, 2000.

[4] C. C. Wang, K. Y. Chi, "Heat transfer and friction characteristics of plain fin-and tube heat exchangers, part I: new experimental data," Int. J. Heat Mass Transfer, vol. 43, pp. 2681-2691, 2000.

[5] C. C. Wang, J. S. Liaw, B. C. Yang, "Airside performance of herringbone wavy fin and- tube heat exchangers - data with larger diameter tube," Int. J. Heat Mass Transfer, vol. 54, pp. 1024-1029, 2011.

[6] W. Pirompugd, C. C. Wang, S. Wongwises, "Finite circular fin method for wavy fin-and-tube heat exchangers under fully and partially wet surface conditions," Int. J. Heat Mass Transfer, vol. 51, pp. 4002-4017, 2008.

[7] L. A. O. Rocha, F. E. M. Saboya, J. V. C. Vargas, "A comparative study of elliptical and circular sections in one- and two-row tubes and plate fin heat exchangers," Int. J. Heat Fluid Flow, vol. 18, pp. 247-252, 1997.

[8] C. W. Lu, J. M. Huang, W. C. Nien, C. C. Wang, "A numerical investigation of the geometric effects on the performance of plate finned-tube heat exchanger", Energy Convers. Manage. vol. 52, pp. 1638-1643, 2011.

[9] A. Zukauskas, "Heat transfer from tubes in cross flow," Adv. Heat Transf., vol. 18, no. 1, pp. 87-159, 1987. 
[10] E. Buyruk, "Numerical study of heat transfer characteristics on tandem cylinders, inline and staggered tube banks in cross-flow of air," Int. Commun. Heat Mass Transf., vol. 29, no. 3, pp. 355-366, 2002.

[11] T.-H. Shih, W. W. Liou, A. Shabbir, Z. Yang, and J. Zhu, "A New K- $\varepsilon$ Eddy-Viscosity Model for High Reynolds Number Turbulent Flows - Model Development and Validation," Computers Fluids. vol. 24, no. 3, pp. 227-238, 1995.

[12] T. Jongen. "Simulation and Modeling of Turbulent Incompressible Flows". PhD thesis. EPF Lausanne, Lausanne, Switzerland. 1992.

[13] R. Deepakkumar, S. Jayavel, "Air side performance of finned-tube heat exchanger with combination of circular and elliptical tubes,” Applied Thermal Engineering, vol. 119, pp. 360-372, 2017. 